\title{
Introduction: Translation and Performance
}

\author{
Anne Malena \\ University of Alberta, Edmonton
}

This issue of TranscUltur $A$ lincludes a variety of articles that reflect how rich and diverse the theme of translation and performance is because they draw from various disciplines, such as music, theatre, comics, poetry, and image studies. While translation itself, of course, can be viewed as performative the aim of this collection is primarily to explore what happens to translation when it is involved in performance. Since performing arts are multimodal, the translator must pay attention to the nonverbal dimensions of a performance, such as gestures, facial expressions, images, movements, visual perspectives, sounds, timing or lighting, in addition to language. In this way, opera translation involves more than libretti and surtitles, song translation more than poetry, drama translation more than dialogue, and film translation more than the constraints dictated by the choice of dubbing or subtitling. The text on which a performance is based does not stand alone since its meaning only achieves its full potential through the performer's interpretation of it. For translators this presents a huge challenge because no matter how apt their lexical choices or how clever their turns of phrase, they always need to consider how suitable those are for the performer. Indeed, the very best textual translation of a song may prove to be unusable if the singer discovers that the words do not match the notes because, for example, the natural accentuation of a particular language interferes with the rhythm of the music.

In an article written over a century ago and still relevant today, the author discusses an example of the kind of difficulties one encounters when "Translating to Music": "Debussy, in the song ' $C$ 'est l'extase langoureuse,' gives a direct imitation of the rolling sound of pebbles under water, in setting the phrase 'Le roulis sourd des cailloux.' The translation, 'Where waves on stormy shores die,' scarcely makes the point clear" (Spaeth 295-296). Readers will find here many more examples of inadequate translations that illustrate how skilful and knowledgeable translators must be in the performing arts. While the need to listen to the music of the language has become somewhat of a cliché among literary translators and translation scholars it bears repeating often outside the field and this issue of TranscUlturAl goes a step further in demonstrating that performance translators must also listen to the language of music, or more generally to the language of performance. After all writers, and most strikingly poets among them, are tuned in to the sounds of language just as much as composers, dramaturgs, of film makers are sensitive to text: they are not opposed to each other nor should they ever be since they all want the same thing, to create something beautiful and meaningful. Jessica Moore, both a poet and a translator, put it most eloquently during an interview. For her, the act of translation, "more than simply knowing two languages," is best illustrated "through the analogy of knowing how to play the piano: the use of ten fingers is no guarantee of concert pianist abilities" (Saklikar 21). 
At least two issues emerge for translators out of situations involving performance: the first, raised by several contributors to this issue, is why bother to translate at all, especially when technology can now provide monolingual spectators with the means to grasp what is happening on stage or on screen through the use of surtitles, subtitles and programme notes. A matter of much debate, it is not our intention to provide a definite answer to this question but we do hope that readers will enjoy discovering the various perspectives assembled here. The second issue concerns whether translators should always be expected to be knowledgeable about the domain or the genre to which belongs the text they are working on. Ideally yes, linguistic knowledge is never enough. In reality, however, while a few translators may be lucky enough to have specialized in the realm of music, theatre or cinema exclusively, most make a living by accepting any work that becomes available in any arts-related disciplines. Furthermore, as Susan Bassnett puts it: "A translator cannot be actor, director, designer and audience all at the same time" (99). It is, therefore, difficult to expect them to always possess the expertise necessary for the production of a translation that adheres to the general criteria of performability. Collaborative translations, or team translations, are now more common for the stage, establishing a now familiar distinction between text-tanslation and stage-translation but such is not the case for all performing arts. In addition, studies of such innovative forms of translations are usually only found under the rubric of the genre to which they belong and must not be confused with the broader category of what has generally been termed "production networks", which are still few and far between despite the fact that these networks "have been identified as the prevailing working environment in present-day translation industry" (Abdallah 11). ${ }^{1}$

Readers will find here a small sample of case studies, discussions of general principles, specific proposals for solutions and presentations of particular challenges, across genres, which illustrate some of the issues discussed above. Some articles (Buhler, Penrod, Trujillo, Siemens, Onita, Cruikshank) are revised versions of papers presented at the fourteenth Annual celebration of International Translation Day, otherwise known as St. Jerome's Day, at the University of Alberta on September 30, 2016. The editorial decision to present the articles in a rather eclectic order reflects the wish to convey the multiplicity of viewpoints and approaches to the problematics of translation in the performing arts without resorting to divisive generic categories. The dossier opens with "The Pitfalls of Musical Translation" by François Buhler, musicologist and translator, who gave the keynote address at the conference. In the extended version included here, readers will appreciate how a professional musician "speaks" the language of music and views textual translation, in art songs and in operas, as necessarily and tightly bound to that first language as intended by composers. While translation has long been limited to providing basic information to audiences in opera performance, with surtitles and their constraints of time and space and libretto translations having traditionnally been very literal (Bassnett 97), Buhler argues that, since the composer has used word painting to make the music fit the text as tightly as possible, the translator ought to strive for a similar effect. This presupposes superior musical knowledge on the part of translators, and the first half of the article covers some of the necessary

\footnotetext{
${ }^{1}$ See also Buzelin and Folaron; Bassnett.
} 
principles in enlightening details. The rest of the paper focuses on a new French translation by the author of Aleko, a one-act opera based on the poem "Tsigany" (The Gipsies) by Pushkin, as a way to illustrate the initial discussion. This contribution will be of interest to musicians and translators alike as well as musicologists and translation scholars while non-specialists will enjoy to learn more about what goes on behind the scenes of performance.

Next, Michaela Wolf calls attention to the performative turn in translation studies from a sociological perspective and discusses the main features of this new turn, as well as its context of the social practice of translation in order to assess to what extent the performative turn generates a new concept of translation better able to meet the political and social requirements of current translation practice. Indeed, to view translation as a social practice becomes paramount in today's increasingly differentiated societies. In carefully weighing the theatricality of social translation and the translation processes in theatre Wolf makes a very valuable contribution to this issue concerned with the methods, practice and consequences of performance translation. Staying with theatre, "Sign Language Interpreting in Theatre: Using the Human Body to Create Pictures of the Human Soul" by Michael Richardson offers a fascinating heuristic look at sign language inerpreted performances or SLIPs in the UK. The author accepts Deaf culture as a genuine social phenomenon, created by people who self-identify as Deaf, and stresses the fact that sign languages are languages to the full linguistic extent of the term, in spite of having no written form, and that they differ from culture to culture just like French or English. The challenges of translating a play into sign language are many because of the visual and embodied nature of the interpretation and Richardson explores Merleau-Ponty's phenomenological concept of perception to arrive at a more satisfactory theoretical model than those currently existing in Interpreting Studies and demonstrate that Wittengstein was correct in claiming that "the human body is the best picture of the human soul."

The next article brings us back to music with a discussion of art song and the problems this genre encounters in translation. Lynn Penrod relates her own experience of the "yellow book" (Schirmer) as a voice student and chorister in order to open a greater dialogue within Translation Studies between researchers and practitioners. While it is fair to ask yet again why songs are translated into English for the purpose of training students and not just learned in the original language, stressing once more the issue of translatability, this essays calls attention to an underdeveloped area in translation studies and the need for further debate. Interestingly, Penrod calls upon two critics born in the $19^{\text {th }}$ century and active until the mid $20^{\text {th }}$ century to provide arguments, according to her still valid today, for the necessity to ensure the "singability" of translated art songs. Drawing an analogy with theatre, she argues that the kind of collaborative translation used for the stage today could very well serve song translators. The last two articles in this section deal with the Japanese visual genre of anime and the mixed media of photography and poetry. Daniel E. Josephy-Hernández takes a close look at the translation of graphemes, or verbal signifiers, in anime both in the original and fansubbed versions. He points out that the discipline of Audiovisual Translation (AVT) has been rapidly expanding in recent years and that the popular genre of anime fits well within it. The fact that his study is at times very technical because of the necessity to explain the genre and what fansubbing entails demonstrates the need for AVT to recognize the research potential in anime. Fascinating is 
Josephy-Hernández' discussion of visual representations of onomatopeia (giongo) and mimetic words (gitaigo), as is his advocating fansubbing for often being more ingenious than the official versions, even when they take extreme liberties, which likely only fans would enjoy. With the last article in this section, "Photographed Metaphors: Meaning, Reference, and Translation in Manoel de Barros," readers will discover the collaboration of this Brazilian poet with photographer Adriana Lafer in their book Arquitetura do silêncio (2015). The author, Axel Pérez Trujillo Diniz, views de Barros' preoccupation with language and expression in these "verbal sketches" as engaging with analytic philosophies of language, as articulated by Gottlob Frege and Willard Van Orman Quine. According to him, objects gain a voice through words and Barros throws a ludic challenge at meaning and reference in his poetry. In the book the boundarie between words and images is blurred, suggesting the indeterminacy of meaning and, therefore, the undecidability of translation as discussed by Quine. In this way the juxtaposition of poetry and out-of-focus photographs amounts not to a straightforward translation between the two but rather to a representation of the very performance of translation.

A set of three articles, entitled "The Curtain Call: Translating Performance in Text and Visual Media Creative Portfolio," closes this dossier on the theme of translation and performance. Introduced by Elena Siemens, these pieces focus on the performance of images, as in fashion publicity, female rap or Cuban cigars, when they undergo a process of cultural translation. First, Siemens discusses the controversial "Be Stupid" advertising campaign for the Italian fashion label Diesel and argues that interpreting these ads is similar to translating poetry, in other words a nearly impossible task. Her description of the "Stupid Might Fail. Smart Doesn't Even Try" ad, depicting a male model plunging headlong into a mailbox, precipitates a series of literary and image associations that include Derrida, her own visit to Moscow, a letter that Marina Tsvetaeva wrote to fellow poet Rilke, and Barthes. Siemens concludes with a reference to Andy Warhol mixing business and art in an act of boldness and merry-making that animates her own collage of mailboxes photographs. Next, Adriana Onita discusses the Chicana rapper Snow Tha Product and how her works deals with issues of race, gender and sexuality through the use of the culturally performative language of rap. The notion of "flipping the script" is central to hip-hop feminist projects that aim to assert female identity, race and sexuality in the male-dominated rap world and disrupt its inherent dichotomies at the same time. In "Inhaling the Nation: The Cultural Translation and Symbolic Performance of the Cigar in Cuba" Stephen Cruikshank shows, through his own poetry and photographs, how the Cuban cigar has been translated in turn into an imagined symbol of nationalism and a racially hybridized Cuban identity, of the postcolonial separation from Spain in the twentieth century, later of the revolucion and recently of a dissident sub-culture called jineterismo, a term which refers to the black market, prostitution and street hustling. For Cruikshank these successive representations of the cigar can be explained by the translatability of the cigar as a cultural object due to its historical signification.

Following these articles related to the theme of this issue is one more on the "Challenges and Strategies in Translating Chinese and English Prepositions into Standard Shona" by Herbert Mushwange. Shona is the language spoken by the Bantu people in Zimbabwe and it does not use prepositions. The author, who is a native Shona speaker, a teacher of Chinese and a linguist, explains that prepositions translated into Shona are, therefore, dropped, replaced or translated by semi 
equivalents. The issue then concludes with two contributions in poetry translation, the first by Wioletta Polanski and two poems by the Polish writer Rafał Podraza and the second by Houssem Ben Lazreg and two poems by the Tunisian poet Sghaïer Ouled Ahmed, and finally three book reviews.

Before inviting readers to scroll down through these excellent pages I wish to thank all contributors for the quality of their work, their help and their patience in seeing this issue to the finish. Months in preparation, this issue would not have seen the day without the dedicated assistance of our newest copy editor, Stephen Cruikshank, who always made himself available and responded quickly to all my queries with efficiency and valuable initiative. Himself a contributor, he also donated one of his marvelous photographs to adorn our cover. ¡Muchas gracias, Stephen! 


\section{REFERENCES}

Abdallah, Kristiina. “Translators' agency in production networks." Translators' Agency. Eds. Tuija Kinnunen and Kaisa Koskinen. Tampere: Tampere University Press, 2010. 11-46.

Bassnett, Susan. "Theatre and Opera." The Oxford Guide to Literature in English Translation. Ed. Peter France. Oxford: Oxford University Press, 2010. 96-102.

Buzelin, Hélène and Debbie Folaron, eds. Translation and Network Studies. Special Issue. Meta 52.4 (2007).

Saklikar, Renée Sarojini. "Literary Translation Revealed.” WRITE: The Magazine of the Writers' Union of Canada. Summer Edition (2016): 21-22.

Spaeth, Sigmund. “Translating to Music.” The Musical Quarterly 1.2 (1915): 291-298. 